\title{
Oesophageal perforation: an unusual complication of a hypoglycaemic episode
}

\author{
H. DAYA \& D. WIJETUNGE \\ Accident and Emergency Department, St George's Hospital, Tooting
}

\section{SUMMARY}

A case of spontaneous oesophageal rupture following vomiting, secondary to a hypoglycaemic episode is reported.

The case is of interest in its presentation and physical signs. It reflects the difficulty in diagnosing a condition associated with considerable morbidity and mortality. The importance of recognition of a pattern of symptoms, physical signs and radiographic findings is emphasized.

\section{INTRODUCTION}

Spontaneous transmural perforation of the oesophagus is classically taught to be associated with a progression of symptoms and signs as originally described by Boerhaave in 1724. He described vividly a sequence of over-indulgence in food and drink followed by forceful vomiting leading to severe chest pain, shock and finally death as observed in a famous Dutch admiral, Von Wassener. Although his case is referred to in the literature as the first case of spontaneous oesophageal rupture, the term 'spontaneous' is misleading.

Due to the varied presentation of this condition and its rarity early suspicion is essential to prevent serious and often fatal complications. The diagnosis is suspected by radiographic findings and confirmed by contrast swallows.

This case reflects the disparity in the presenting features and emphasizes the importance of recognition of physical signs and radiographic abnormalities. The suitability of the term 'spontaneous' is discussed as usually there are predisposing factors.

\section{CASE REPORT}

A 17-year-old diabetic mixed Caucasian male presented to the Emergency Depart- 
ment with a 12-h history of severe retrosternal pain radiating into the neck. The pain was pleuritic in character and was exacerbated by coughing and swallowing. He had had a hypoglycaemic episode the previous day during which he vomited.

There was no past history of gastrointestinal illness, foreign body ingestion or recent surgery.

On examination he appeared unwell and in pain. He was febrile with a temperature of $37.8^{\circ} \mathrm{C}$. He adopted a position of sitting up with his neck flexed on his shoulders. Extension of the neck and palpation of the laryngeal cartilages elicited pain. Cardiovascular examination revealed crackling sounds associated with normal heart sounds (Hammans sign).

Chest and lateral neck radiological examination clearly displayed the presence of air in the retropharyngeal space and the mediastinum. His white cell count was slightly elevated at $11.9 \times 101^{-1}$. The patient was admitted with a diagnosis of spontaneous rupture of the oesophagus and managed conservatively with intravenous antibiotics. An omnopaque swallow performed the next day failed to demonstrate a leak. Oral feeding was introduced. Further radiographs showed a resolving pneumomediastinum and he was discharged 3 days later (Figs 1 \& 2).

\section{DISCUSSION}

Foreign body ingestion, iatrogenic causes and underlying oesophageal pathology are aetiological factors predisposing to oesophageal perforation (Patton et al., 1979). These have an understandable link. Pressure induced factors are less well understood, yet they are typical of Boerhaaves syndrome (Walker et al., 1985). Often these symptoms are not volunteered by the patient and direct questioning is necessary, as in this case. Vomiting is a common symptom yet rarely does oesophageal rupture complicate it. More common is the Mallory Weiss tear which

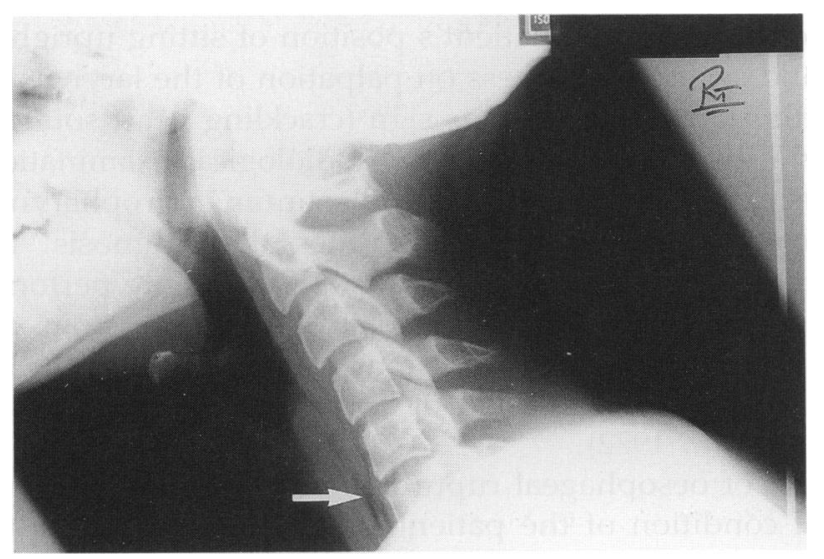

Fig. 1. Lateral neck radiograph demonstrating air in retropharyngeal space and loss of cervical lordosis. 


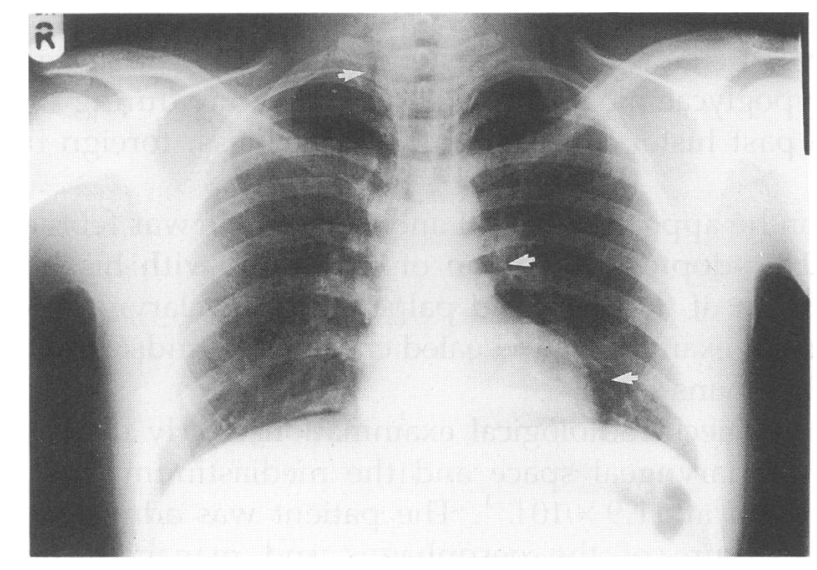

Fig. 2. Chest radiograph demonstrating pneumo-mediastinum.

does not penetrate serosa. It has been suggested that if the oesophagus is diseased a complete tear results due to weakened oesophageal musculature or fibrosis. In a series reported by Patton et al. (1979), 13 out of 14 patients had a previous history of hiatus hernia or duodenal ulceration. Walker (1985) reported that preceding gastrointestinal upset was a common feature in his series. Another postulation is that a failure of the proximal oesophageal sphincter to relax due to neuromuscular incoordination results in a further increase in oesophageal distension (Rogers et al., 1972). Alcohol excess may be an associated factor. There still, however,? remain cases where there are no significant preceding factors.

The morbidity of this condition necessitates prompt diagnosis. Shock, mediastinitis, septicaemia and death often complicate this condition (Abbot et al., 1970). The history is variable and other diagnoses such as perforated duodenal ulceration, dissecting aneurysm and myocardial infarction are suspected, delaying appropriate treatment. The physical signs do not always follow a pattern and are sometimes minimal. In this case, it was the patient's position of sitting upright with the neck flexed forwards and severe tenderness on palpation of the laryngeal cartilages that alerted the admitting doctor. Hammans sign (crackling heart sounds) and surgical emphysema may also be present. It is the radiological examination of the chest and neck demonstrating free air in the mediastinum, retropharyngeal space and occasionally subcutaneous tissue that indicates the diagnosis. Atelectasis and pleural effusion may also be present. Contrast swallows are performed to confirm the diagnosis and the site of perforation. Failure to demonstrate a leak does not necessarily exclude the diagnosis as the tear may reseal. However if clinical suspicion is high and the patient shows no sign of improvement repeat swallows must be performed (Rogers et al., 1972).

The management of oesophageal rupture is usually surgical, however, in cases where the clinical condition of the patient is stable, conservative management is effective. Spontaneous pneumomediastinum may often be confused with oesophageal perforation as the presenting features are similar. Spontaneous mediastinum results from an increase in alveolar pressure resulting in its rupture. The 
air then spreads along the adventitia of pulmonary vessels extending into the mediastinum. Clinical findings and radiographic investigation allow the two to be differentiated. In particular the severity of the pain and its association with vomiting suggest oesophageal rupture. Radiographic findings of mediastinal air extending beneath the parietal pleura over the left hemidiaphragm and along the lateral edge of the aorta (as demonstrated in this case) are more commonly found in oesophageal rupture (Rogers et al., 1972; Granich et al., 1983). This case highlights the difficulty in the diagnosis of spontaneous oesophageal perforation and serves to refresh those, working in the accident and emergency setting, of the importance of physical signs and radiographic findings.

\section{REFERENCES}

Abbot O. A., Mansour K. R., Logan W. D., Hatcher C. R. \& Symbos P. N. (1970) Atraumatic so called 'spontaneous' rupture of the oesophagus. Journal of Thoracic and Cardiovascular Surgery 59, 67-83.

Boerhaave H. (1955) Atrocis nec descripti prius, morbi historia. Secunam medicae leges conscripta. Lugduni batavorum boutestenania 1724. (Translated by Derbes V. J. \& Mitchell R. E.). Bulletin of the Medical Librarians Association 43, 217-240.

Granich M. S., Klotz R. E., Lofgren M. D., Partlow R. C. \& Di Gregorio L. I. (1983) Spontaneous retropharyngeal and cervical subcutaneous emphysema in adults. Archives of Otolaryngology 109, $701-704$.

Patton A. S., Lawson D. W., Shannon J. M., Risley T. S. \& Bixby F. E. (1979) Reevaluation of the Boerhaaves Syndrome. Antercian Journal of Surgery 137, 561-565.

Rogers L. F., Puig W., Dooley B. N. \& Cuello L. (1972) Diagnostic considerations in mediastinal emphysema: a pathophysiologic-roentgenolic approach to Boerhaaves syndrome and spontaneous pneumomediastinum. American Journal of Radiology 115(3), 495-571.

Walker W. S., Cameron E. W. J. \& Walbaum P. R. (1985) Diagnosis and management of spontaneous transmural rupture of the oesophagus (Boerhaaves Syndrome). British Journal of Surgery 172, $204-207$. 